\title{
Yuhan Sohrab-Dinshaw Vevaina. Resurrecting the Resurrection. Eschatology and Exegesis in Late Antique Zoroastrianism
}

\section{Mihaela Timus}

\section{(2) OpenEdition} Journals

Édition électronique

URL : http://journals.openedition.org/abstractairanica/40808

DOI : $10.4000 /$ abstractairanica.40808

ISSN : 1961-960X

Éditeur :

CNRS (UMR 7528 Mondes iraniens et indiens), Éditions de l'IFRI

Édition imprimée

Date de publication : 1 décembre 2013

ISSN : 0240-8910

Référence électronique

Mihaela Timus, « Yuhan Sohrab-Dinshaw Vevaina. Resurrecting the Resurrection. Eschatology and Exegesis in Late Antique Zoroastrianism », Abstracta Iranica [En ligne], Volume 32-33 | 2013, document 312, mis en ligne le 01 juillet 2016, consulté le 26 septembre 2020. URL : http:// journals.openedition.org/abstractairanica/40808; DOI : https://doi.org/10.4000/abstractairanica 40808

Ce document a été généré automatiquement le 26 septembre 2020.

Tous droits réservés 


\title{
Yuhan Sohrab-Dinshaw Vevaina. Resurrecting the Resurrection. Eschatology and Exegesis in Late Antique Zoroastrianism
}

\author{
Mihaela Timus
}

\section{RÉFÉRENCE}

Yuhan Sohrab-Dinshaw Vevaina. « Resurrecting the Resurrection. Eschatology and Exegesis in Late Antique Zoroastrianism », in : C. A. Bromberg, N. Sims-Williams, U. Sims-Williams, eds., BAI: Iranian and Zoroastrian Studies in Honor of Prods Oktor Skjorvø, vol. 19, 2005 [2009], Detroit (Michigan), Iowa State University Press, 2009, p. 215-223.

1 Par des arguments bien fondés, l'A. propose un renouvellement de la réflexion sur l'eschatologie iranienne, dont l'absence pendant les dernières décennies a été déplorée par J. Kellens (2006). Il insiste sur la continuité des expressions attestant la croyance à la résurrection, entre l'Avesta et les commentaires pehlevis. Par cela, il esquisse aussi une nouvelle perspective sur un atelier ouvert de nos jours, dans le cadre des études iraniennes, à savoir la configuration et la compréhension du caractère spécifique de l' exégèse zoroastrienne, toute différente par rapport aux autres traditions monothéistes. Quelques acquis de l'article: 1 . La correspondance intertextuelle précise entre le $D k$. 9.46.1-5 et le FrWestergaard; 2. Une perspective intéressante sur la corporalité eschatologique, en l'occurrence l'emploi du m.p. kālbod dans le Dk. 9, afin de désigner les formes des entités démoniaques. Il s'agit ici d'un autre terme du vocabulaire daēvique zoroastrien, à rajouter à une liste plus longue. (En complément, il convient de préciser que la définition de ce terme est donnée dans le $D k$. 3.105, alors que le $\breve{S} G W 8.30$ lui assigne un rôle relativement neutre : «la forme ( $k a \bar{l} l b o d)$, l'espèce, la largeur d'un être »). 3. Reprise de la question de l'importance de la numérologie symbolique. Depuis Friedrich Windischmann jusqu'à Mary Boyce, on tente de déchiffrer le mystère du 
chiffre 57 qui enferme en énigme la biographie mythique de Sōšān. L'A. réoriente la raison vers un passage de l'Anthologie de Zādspram (28.7), à lire en connexion avec Yasna 54.1-2, et en écartant ainsi la tentation de la spéculation futile.

\section{AUTEURS}

\section{MIHAELA TIMUS}

Institut d'Histoire des Religions, Bucarest 